\title{
Spatial Distribution of Parkinson's Disease Prevalence in Québec by Hydrographic Region
}

\author{
Stephanie Rebecca Susser, Fabien Gagnon
}

\begin{abstract}
The association between environmental exposures and Parkinson's disease continues to garner interest. In the late 1980s, Barbeau et al. reported in the Canadian Journal of Neurological Sciences a heterogeneous distribution of Parkinson's disease cases across the province of Québec by hydrographic region. Here we report the findings of a validation study based on data obtained from the Québec medication insurance program - information which was unavailable to the previous group. Similar to Barbeau et al., our analysis showed a heterogeneous distribution of cases across the province with higher prevalence in the same region of interest, in addition to other areas.

RÉSUMÉ: Distribution géographique de la prévalence de la maladie de Parkinson selon les bassins hydrographiques du Québec. L'association entre la maladie de Parkinson et l'exposition à divers milieux de vie continue à susciter un intérêt. À la fin des années 1980, dans le Canadian Journal of Neurological Sciences, Barbeau et ses collaborateurs signalaient, dans le cas du Québec, une distribution hétérogène des cas de maladie de Parkinson en fonction de ses régions hydrographiques. Dans cette étude de validation reposant sur des données obtenues auprès de la Régie de l'assurance maladie du Québec (RAMQ), nous voulons faire état ici de nos conclusions. À noter que ces données n'étaient alors pas accessibles aux précédents chercheurs. À l'instar de Barbeau et de ses collaborateurs, notre analyse a permis de montrer une distribution hétérogène de cas à l'échelle de la province, notamment une prévalence plus élevée de cas dans une région spécifique ayant suscité notre intérêt mais aussi ailleurs au Québec.
\end{abstract}

Keywords: Parkinson's disease, Epidemiology, Hydrographic basin

doi:10.1017/cjn.2018.24

Can J Neurol Sci. 2018; 45: 478-480

Potential environmental factors involved in the development of Parkinson's disease remain under study. ${ }^{1}$ In 1983, chemical-induced chronic Parkinsonism was described in four young Californians who injected MPTP (1-methyl-4-phenyl-1,2,5,6-tetrahydropyridine), a synthetic by-product of a meperidine analog that transforms within astrocytes to MPP+, a molecule structurally similar to Paraquat. ${ }^{2-3}$ Proposed toxicological mechanisms associated with pesticideinduced neurodegeneration have been described, ${ }^{4}$ and associations between Parkinson's disease and agriculture-related risk factors such as rural-living, well-water consumption and pesticide use have garnered additional attention recently. ${ }^{5-6}$ In the late $80 \mathrm{~s}$, the Canadian Journal of Neurological Sciences published the findings of a descriptive study examining the spatial distribution of Parkinson's disease by hydrographic basin in rural areas of the Province of Québec. ${ }^{7}$ Specifically, the authors of this paper estimated the prevalence of Parkison's disease in each basin using data compiled from doctor's visits' billing, sales of levodopa, death certificates and surveys of neurologists' practice, revealing a clustering in region 3 (please refer to Figure 1) — an area known for its apple orchards and commercial production of vegetables, the "Garden of Quebec."7 Here we report findings of a validation of the Barbeau study using information obtained from the Québec medication insurance program, which covers all Quebeckers by default (opt-out possible) after the age of 65 years.

In accordance with Barbeau's approach, ${ }^{7}$ we concentrated our analyses on non-urban areas. Population figures for each municipality were obtained from the Quebec institute of statistics (institute de statistiques du Québec), and municipalities with a population over 50,000 were excluded. The remaining municipalities were grouped according to hydrographic basin using information provided by the Quebec Environmental ministry (Ministère du développement durable, environnement et lutte contre les changements climatiques). Numerator (users of levodopa and related molecules, aged 65 years and older) and denominator (enrolled individuals aged 65 years and older) information was obtained from the RAMQ (Régie de l'assurance maladies de Québec) based on these municipality groupings. RAMQ was able to locate the number of cases (for 2013, 2014 and 2015) and covered individuals aged 65 years and older (for 2014) in each municipality, presenting a sum over all the retained municipalities for each basin. These data are presented in Table 1. Note that user information is presented as an average over the 3 years provided, and that no data were available for regions 9 (James Bay and Hudson's Bay), 10 (Ungava Bay) and 11 (Labrador Sea).

A $\chi^{2}$ analysis was used to evaluate the overall relationship between hydrographic basin and use of levodopa and analogs.

From the Département clinique de santé publique du Centre intégré de santé et de services sociaux de Laval, Laval, Québec, Canada (SRS, FG); Harvard T.H. Chan School of Public Health, Boston, Massachusetts (SRS); Centre de recherche du Centre hospitalier universitaire de Sherbrooke, Sherbrooke, Québec, Canada (FG)

Received August 31, 2017. Final Revisions Submitted February 16, 2018. Date of AcCeptance February 27, 2018.

Correspondence to: S. R. Susser, Direction de santé publique du CISSS de Laval, 800 boul Chomedey - Tour A, Laval, H7V 3Y4. Email: sr.susser_reg13@ssss.gouv.qc.ca 


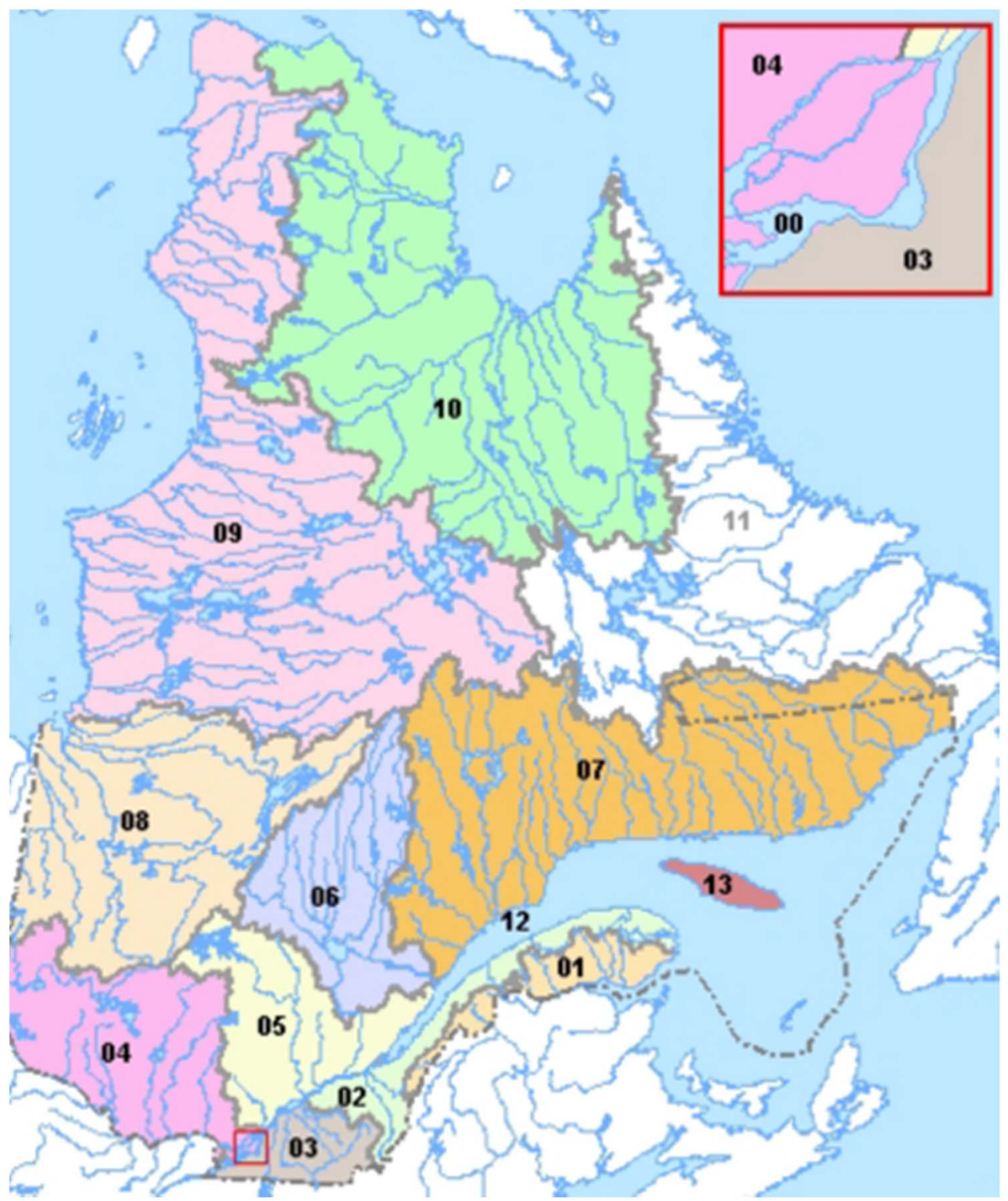

Figure 1: Hydrographic regions of the province of Québec, Canada. Source: MDDELCC website: http:// www.mddelcc.gouv.qc.ca/eau/bassinversant/regionshydro/index.ht

Following this, in order to identify regions that demarcate themselves from the others in terms of prevalence, individual $\chi^{2}$ statistics were calculated to evaluate the association for each region individually versus all other regions combined. Data management was done with google spreadsheet, and all calculations were performed with the use of STATA version 14.

Total estimated Parkinson's disease prevalence across hydrographic regions was found to be 945.61 cases per 100,000 registered regime users over the age of 65 years (Table 1). The $\chi^{2}$ statistic for the overall association between levodopa use and hydrographic region was statistically significant $(p<0.0000)$. Analyses for individual regions versus all regions combined showed statistically significant departures for (expressed in cases per 100,000 users, $p<0.05$ ) region 3 (993.56), region 5 (820.10), region 6 (1121.61), region 8 (1087.84) and region 13 (443.92).

This study illustrates an uneven distribution of prevalent Parkinson's disease cases across the hydrographic regions of the province of Québec, although we cannot correct for differences in age distribution between regions. It is unlikely that this pattern is due to a differential distribution of neurologists across the province. Recent medical workforce data for the province of Québec show that out of 256 adult neurologist positions available only 18 were vacant at the end of 2017, with six of these vacancies in Montérégie, an area that roughly corresponds to hydrographic region no. 3 . $^{8}$ As with the study by Barbeau et al, we found an excess of levodopa users in region 3 (Saint Laurent Sud-Ouest) in addition to some other regions. The estimated overall prevalence of Parkinson's disease in this study sits within published estimates based on the Canadian Community Health Survey. ${ }^{9}$ Specifically, 2010-2011 data show estimates (number of cases per 100,000 people) of 410,1030 and 1420 for the $60-69,70-79$ and $80+$ age groups, respectively. ${ }^{9}$ This suggests that levodopa remains a good proxy for the presence of Parkinson's disease in this age set, in line with current pharmacologic practice to treat individuals over the age of 65 years with levodopa instead of dopamine agonists. ${ }^{10}$ 
Table 1: Prevalence of levodopa use among registered regime users $(\geq 65)$ by hydrographic region

\begin{tabular}{|c|c|c|c|c|}
\hline & $\begin{array}{l}\text { No. levodopa } \\
\text { users }(\geq 65)^{*}\end{array}$ & $\begin{array}{c}\text { No. levodopa } \\
\text { non-users }(\geq 65)^{*}\end{array}$ & $\begin{array}{l}\text { No. registered regimes users } \\
(\geq \mathbf{6 5}) \text { in } 2014\end{array}$ & $\begin{array}{c}\text { Prevalence (per } 100,000 \text { registered } \\
\geq 65 \text { regime users) }\end{array}$ \\
\hline \multicolumn{5}{|l|}{ Hydrographic region } \\
\hline 01 (Bale des Chaleurs et Percé) & 197.67 & 19,698 & 19,896 & 993.50 \\
\hline 02 (Saint-Laurent sud-est) & 882.67 & 92,867 & 93,750 & 941.51 \\
\hline 03 (Saint-Laurent sud-ouest) & 1491.67 & 148,642 & 150,134 & $993.56^{* * *}$ \\
\hline 04 (Outaouais et Montréal) & 1222.33 & 126,273 & 127,495 & 958.73 \\
\hline 05 (Saint-Laurent nord-ouest) & 784.33 & 94,858 & 95,642 & $820.10^{* * *}$ \\
\hline 06 (Saguenay et lac Saint-Jean) & 247 & 21,775 & 22,022 & $1121.61 * * *$ \\
\hline 07 (Saint-Laurent nord-est) & 94.33 & 12,796 & 12,980 & $731.83 * * *$ \\
\hline 08 (Baie des Hannah et de Rupert) & 214 & 19,458 & 19,672 & $1087.84 * * *$ \\
\hline 12 (iles du fleuve Saint-Laurent) & 22 & 2377 & 2399 & 917.05 \\
\hline 13 (iles du golfe Saint-Laurent) & 11.33 & 2542 & 2553 & $443.92 * * *$ \\
\hline Total** & 5167.33 & 541,286 & 546,453 & 945.61 \\
\hline
\end{tabular}

*Calculated as the average number of registered levodopa users (first column) and non-users (second column) aged $\geq 65$ for the years 2013,2014 and 2015.

**Total for all 13 hydrographic regions excluding the northern areas 9 (Baies James et d'Hudson), 10 (Baie d'Ungava) (where no cases were reported) and 11 (Labrador sea-uninhabited), $\chi^{2}$ levodopa use $(\geq 65)$ versus region $p<0.0000$.

$* * * \chi^{2}$ region versus all others, $p<0.05$.

We did not find a correlation between the density of pesticide use in kilograms sold divided by hectares covered $(\mathrm{kg} / \mathrm{ha})$ in 1982 and the prevalence of levodopa use by hydrogaphic basin (data not shown). ${ }^{11}$ A recent systematic review and meta-analysis examining the relationship between rural living, well-water consumption, farming and pesticide use revealed that associations were present in the literature but were inconsistent. The authors highlighted the need for a better characterization of the onset of Parkinson's disease, ideally through enrollment of individuals close to the time of diagnosis in order to ensure that exposure precedes disease onset. ${ }^{6}$ Indeed, the major weakness of this study is the use of prevalence data, which precludes any causal inference owing to the lack of temporal information. Further work must involve the use of incident cases, with age adjustment.

\section{ACKNOWLEDGMENT}

Funding to obtain data from the Régie de l'assurance maladie du Québec (RAMQ) was generously provided by the CHUS (centre hospitalier de l'université de Sherbrooke) research center. Marie-Lise Paquin of the MDDELCC provided the hydrographic basin data, Marie-Claude Devin and France Bourque of the RAMQ graciously spent time classifying the cases according to region and compiled the final data set. Dr. Francis Earl Cook of the Harvard T.H. Chan School of Public Health generously provided thoughtful comments and guidance throughout.

\section{Disclosure}

Neither of the authors has anything to disclose.

\section{STATEMENT Of AuthorshiP}

FG conceived the idea for the study, FG and SRS outlined the methods, SRS performed data cleaning and analysis and wrote the initial draft of the article. FG and SRS worked together on subsequent drafts of the paper.

\section{REFERENCES}

1. Wirdefeldt K, Adami H-O, Cole P, Trichopoulos D, Mandel J. Epidemiology and etiology of Parkinson's disease: a review of the evidence. Eur J Epidemiol. 2011;26:S1-58.

2. Langston JW, Ballard P, Tetrud JW, Irwin I. Chronic Parkinsonism in humans due to a product of meperidine-analog synthesis. Science. 1983;219(4587):979-80.

3. Hatcher JM, Pennel KD, Miller GW. Parkinson's disease and pesticides: a toxicological perspective. Trends Pharmacol Sci. 2008; 29(6):322-329.

4. Baltazar MT, Dinis-Oliveira RJ, de Lourdes Bastos M, Tsatsakis AM, Duarte JA, Carvalho F. Pesticides exposure as etiological factors of Parkinson's disease and other neurodegenrative diseases - a mechanistic approach. Toxicol Lett. 2014;230(2):85-103.

5. Pezzoli G, Cereda E. Exposure to pesticides or solvents and risk of Parkinson disease. Neurology. 2013;80(22):2035-41.

6. Breckenbridge CB, Berry C, Chang ET, Sielken RL Jr, Mandel JS. Association between Parkinson's disease and cigarette smoking, rural living, well-water consumption, farming and pesticide use: systematic review and meta-analysis. PLoS One. 2016;11(4):e0151841.

7. Barbeau A, Roy M, Bernier G, Campanella G, Paris S. Ecogenetics of Parkinson disease: prevalence and environmental aspects in rural areas. Can J Neurol Sci. 1987;14(1):36-41.

8. Ministère de la Santé et des Services sociaux du Québec. Plans d'effectifs médicaux (PEM) en spécialité en date du 2017-12-19. 2017. 25 p. Available at: http://www.msss.gouv.qc.ca/sujets/ organisation/medecine-au-quebec/medecine-specialisee/prem/ documents/toutes_specialites_2017-12-19.pdf, accessed January 19, 2018.

9. Public Health Association of Canada. Prevalence and incidence of neurological conditions: mapping connections - an understanding of neurological conditions in Canada, 2014. 98 p. Available at: www.phac-aspc.gc.ca/publicat/cd-mc/mc-ec/assets/ pdf/mc-ec-eng.pdf, accessed April 5, 2018.

10. Tarsy D, Hurtig HI, Dashe JF. Pharmacologic treatment of Parkinson disease. 2017. UpToDate. Available at: https://www.uptodate. com/contents/pharmacologic-treatment-of-parkinson-disease, accessed April 5, 2018.

11. Godon D, Lajoie P, Nadeau D. Atlas de l'Utilisation des Pesticides en Agriculture au Québec. Département de santé communautaire, Centre Hospitalier de l'Université Laval, Service Santé et environnement. 1987. $42 \mathrm{p}$. 